\title{
Sensitivity of Mission Energy Consumption to Turboelectric Distributed Propulsion Design Assumptions on the N3-X Hybrid Wing Body Aircraft
}

\author{
James L. Felder ${ }^{1}$ and Michael T. Tong ${ }^{2}$ \\ NASA Glenn Research Center, Cleveland, Ohio, 44135, USA \\ Julio $\mathrm{Chu}^{3}$ \\ NASA Langley Research Center, Hampton, Virginia, 23681, USA
}

\begin{abstract}
In a previous study by the authors it was shown that the N3-X, a 300 passenger hybrid wing body (HWB) aircraft with a turboelectric distributed propulsion (TeDP) system, was able to meet the NASA Subsonic Fixed Wing (SFW) project goal for $\mathbf{N}+3$ generation aircraft of at least a $60 \%$ reduction in total energy consumption as compared to the best in class current generation aircraft. This previous study combined technology assumptions that represented the highest anticipated values that could be matured to technology readiness level (TRL) 4-6 by 2030. This paper presents the results of a sensitivity analysis of the total mission energy consumption to reductions in each key technology assumption. Of the parameters examined, the mission total energy consumption was most sensitive to changes to total pressure loss in the propulsor inlet. The baseline inlet internal pressure loss is assumed to be an optimistic $0.5 \%$. An inlet pressure loss of $3 \%$ increases the total energy consumption $9 \%$. However changes to reduce inlet pressure loss can result in additional distortion to the fan which can reduce fan efficiency or vice versa. It is very important that the inlet and fan be analyzed and optimized as a single unit. The turboshaft hot section is assumed to be made of ceramic matrix composite (CMC) with a $3000 \mathrm{~F}$ maximum material temperature. Reducing the maximum material temperature to $2700 \mathrm{~F}$ increases the mission energy consumption by only $1.5 \%$. Thus achieving a $3000 \mathrm{~F}$ temperature in CMCs is important but not central to achieving the energy consumption objective of the N3-X/TeDP. A key parameter in the efficiency of superconducting motors and generators is the size of the superconducting filaments in the stator. The size of the superconducting filaments in the baseline model is assumed to be 10 microns. A 40 micron filament, which represents current technology, results in a $200 \%$ increase in $\mathrm{AC}$ losses in the motor and generator stators. This analysis shows that for a system with $\mathbf{4 0}$ micron filaments the higher stator losses plus the added weight and power of larger cryocoolers results in a $4 \%$ increase in mission energy consumption. If liquid hydrogen is used to cool the superconductors the $\mathbf{4 0}$ micron fibers results in a $200 \%$ increase in hydrogen required for cooling. Each pound of hydrogen used as fuel displaces 3 pounds of jet fuel. For the N3-X on the reference mission the additional hydrogen due to the increase stator losses reduces the total fuel weight $10 \%$. The lighter fuel load and attendant vehicle resizing reduces the total energy consumption more than the higher stator losses increase it. As a result with hydrogen cooling there is a slight reduction in mission energy consumption with increasing stator losses. This counter intuitive result highlights the need to consider the full system impact of changes rather than just at the component or subsystem level.
\end{abstract}

\footnotetext{
Nomenclature

$A D P=$ Aerodynamic Design Point flight condition

${ }^{1}$ Aerospace Engineer, Systems Engineering and Analysis Division, 21000 Brookpark Rd/MS 86-4 Senior Member.

${ }^{2}$ Aerospace Engineer, Aeropropulsion Division, 21000 Brookpark Rd/MS 5-11.

${ }^{3}$ Aerospace Engineer, Aeronautics Systems Analysis Branch, MS 442 .
}

1

American Institute of Aeronautics and Astronautics 


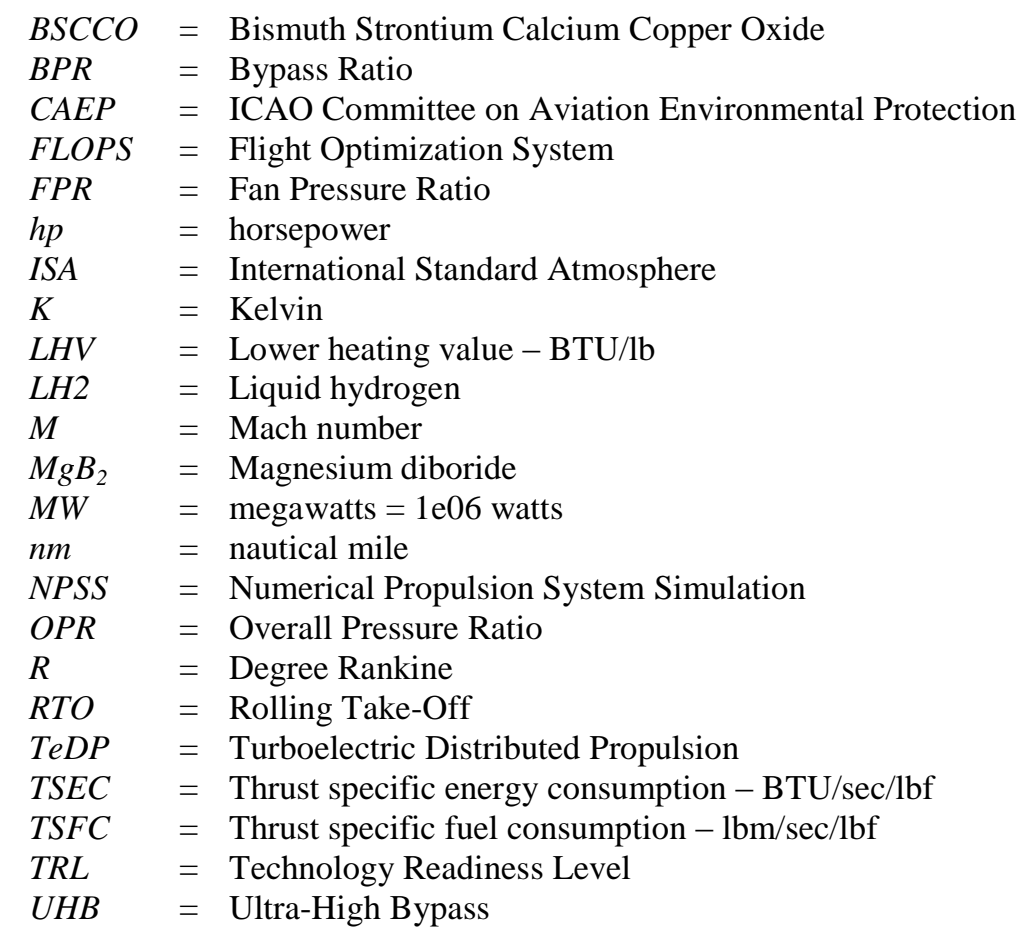

\section{Introduction}

$\mathrm{T}$ HE NASA Aeronautics program has defined ambitious goals for the next three generations of aviation (identified as $\mathrm{N}+1, \mathrm{~N}+2, \mathrm{~N}+3)^{1}$. The $\mathrm{N}+3$ generation goals are a $-71 \mathrm{~dB}$ noise reduction relative to stage 4 noise limits, an $80 \%$ reduction in NOx emissions below the ICAO Committee on Aviation Environmental Protection (CAEP)/6 levels during take-off and landing (LTO), an 80\% reduction in in-route NOx emissions and a $60 \%$ reduction in total mission energy consumption relative to the base in class current aircraft. Total mission energy consumption is used as the metric rather than fuel mass to correctly account for fuels such as liquefied natural gas and especially hydrogen which have lower heating values considerably different from that of standard jet fuel, and which would show an artificial advantage if only compared on a mass basis as well as stored energy devices such as batteries which are "free" when measured against a mass consumption metric. There is on-going discussion about where to draw the control volume boundary around the energy used by the aircraft. For the analysis represented in this paper that boundary was assumed only to be around the aircraft and so the energy consumed represents only the chemical energy present in the fuel actually on board the aircraft. In a hydrogen cooled system, the hydrogen is counted as part of the fuel not the propulsion system sense ultimately it will be burned in the turboshaft. A full accounting of the energy expenditures could include the energy required to extract, transport, refine, liquefy and/or manufacture the fuel. But if the energy required to generate the electricity that charges the batteries or to split water, liquefy the hydrogen is included in the energy balance, then so should the energy required to extract, transport, and refine the jet fuel that it replaces.

Meeting the N+3 goals will take innovative approaches to aircraft and propulsion technology and design. One approach being examined by a team at the NASA Glenn and Langley Research Centers is the combination of a hybrid wing body aircraft with a turboelectric distributed propulsion (TeDP) system that we have called the N3- $\mathrm{X}^{2}$. The design parameters for the baseline TeDP system represents the highest values for each parameter anticipated to reach a technology readiness level (TRL) ${ }^{3} 4-6$ by 2030 . The key design parameters and the baseline values are given in Table 1. This paper presents the change in total mission energy consumption resulting from perturbations to these key performance parameters. The goal of this paper is to provide a resource to the community that allows the changes in component level performance due to new technologies and approaches to be readily translated to the change in mission energy consumption. From there is it simple to calculate the total mission energy consumption and then to compare that to the B777-200LR mission energy consumption to assess the impact of the new technology against the $\mathrm{N}+3$ energy reduction metric. 


\section{Baseline N3-X/TeDP Configuration}

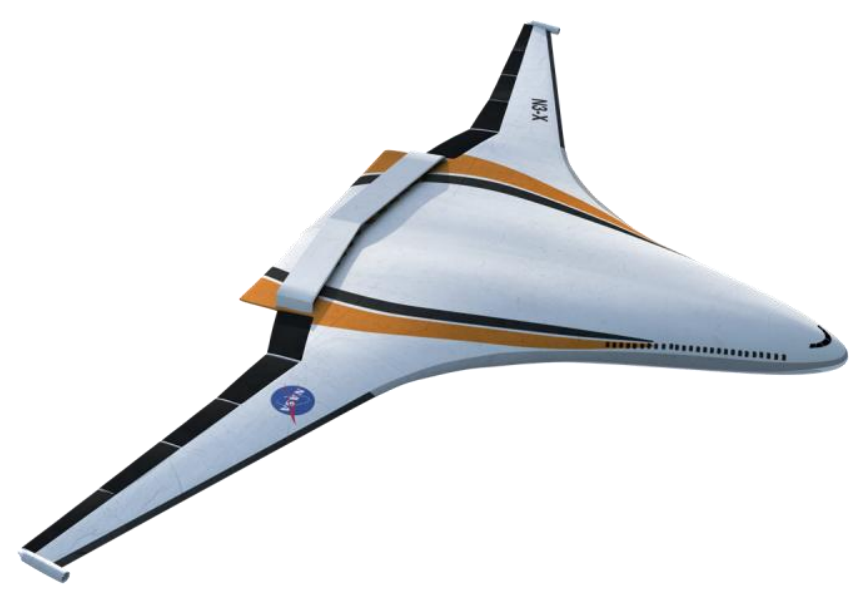

Figure 1 N3-X with Turboelectric Distributed Propulsion System

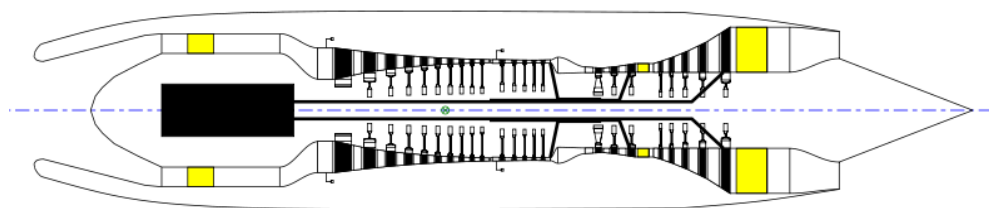

Figure 2 Turbogenerator with 3-spool Turboshaft Engine Driving a Superconducting Generator

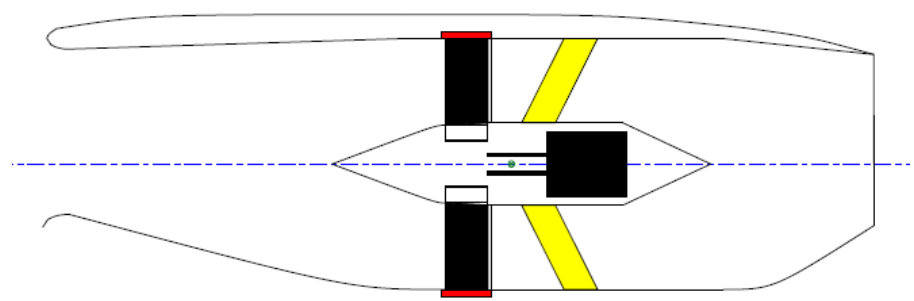

Figure 3 Propulsor with Superconducting Motor Driven Fan

The N3-X, shown in Figure 1, is sized to carry 300 passengers over a range of $7500 \mathrm{~nm}$ with a cruise Mach number of 0.84. A NASA model of an aircraft in the Boeing B777-200LR class is used as the current generation baseline against which the N3-X mission energy consumption is compared. The turboelectric propulsion system consists of two 28,500 hp turboshaft engines driving superconducting electrical generators in nacelles mounted on the wingtips, a cross section of which is illustrated in Figure 2. Collectively, the generators make approximately 42 megawatts (MW) of electrical power at the rolling take-off (RTO) condition which is sea level, Mach number 0.3, and 27 degrees F above the International Standard Day (ISA) temperature. The electrical power is transmitted along a redundant superconducting electrical distribution grid to a 60 foot wide array of propulsors embedded in the upper trailing edge of the fuselage section of the aircraft. In the baseline design there are 14 propulsors in the array, each with a fan driven by a superconducting motor. A cross section of one of the propulsors is illustrated in Figure 3 . The individual inlets and nozzles of each propulsor are 2-D in cross section at the inlet and exit planes, and transition to and from circular at the fan. Collectively, the propulsor inlets and nozzles constitute a single continuous mail slot inlet and nozzle. Flow splitters just behind the inlet leading edge separate the flow for each propulsor and extend aft to the nozzle exit plane. 
Two different combinations of superconducting material and cooling approaches were examined. The first configuration consists of barium strontium calcium copper oxide (BSCCO) superconducting material with a critical temperature of $108 \mathrm{~K}$ and working temperature of approximately $58 \mathrm{~K}$ paired with a reverse Brayton cycle refrigeration system (referred to as a cryocooler). The specific power of the cryocoolers is assumed to be $5 \mathrm{lbs}$ per input horsepower. As cooling load changes, so too does input horsepower required to drive the cryocooler and thus so too does the weight. The second configuration consists of magnesium diboride $\left(\mathrm{MgB}_{2}\right)$ superconducting material with a critical temperature of $39 \mathrm{~K}$ and a working temperature of approximately $28 \mathrm{~K}$ paired with a liquid hydrogen (LH2) cooling system. Once the hydrogen has been used for cooling it is then injected into the turboshaft engines driving the generators and represents part of the fuel of the vehicle. For this reason the weight of the hydrogen coolant is included in the total fuel weight and fuel energy. For the baseline system the liquid hydrogen represents about 3\% by weight of the total fuel. Due to the much higher energy content, the hydrogen represents about $9 \%$ of the total fuel energy. As the cooling needs changes due to the power of the device being cooled or due to the efficiency of these devices the amount of hydrogen changes as well. In all cases only enough hydrogen is carried to meet cryogenic cooling requirements with the rest of the fuel energy coming from conventional jet fuel. The insulated tanks that hold the hydrogen are assumed to weight $1 / 2$ the weight of the hydrogen itself. The LH2 tank weights are included in the propulsion system weight. When the amount of hydrogen required changes, so too then does the tank weight. Only the change in tank weight is reflected in the propulsion weight change. The change in hydrogen weight is reflected in the change in fuel weight and fuel energy.

\begin{tabular}{|l|l|l|}
\hline Component & Parameter & Baseline Design Value \\
\hline Propulsor Inlet & dP/P & $0.5 \%$ \\
\hline Fan & Pressure Ratio (FPR) & 1.30 \\
\hline Fan & Undistorted adiabatic efficiency & $95.35 \%$ \\
\hline Fan & Boundary layer ingestion distortion efficiency penalty & $1 \%$ \\
\hline CompL & Polytropic efficiency & $93.25 \%$ \\
\hline CompH & Polytropic efficiency & $93.25 \%$ \\
\hline CompH & Max exit total temperature (T3) & $1350 \mathrm{~F}(1809.67 \mathrm{R})$ \\
\hline Burner & Exit total temperature & $3000 \mathrm{~F}(3459.67 \mathrm{R})$ \\
\hline TurbH & Polytropic efficiency & $93.0 \%$ \\
\hline TurbL & Polytropic efficiency & $93.0 \%$ \\
\hline TurbP & Polytropic efficiency & $92.4 \%$ \\
\hline Motor & Stator loss fraction for $4064 \mathrm{hp}$ and $4400 \mathrm{rpm}$ & 0.000280 \\
\hline Generator & Stator loss fraction for $28505 \mathrm{hp}$ and $8000 \mathrm{rpm}$ & 0.000224 \\
\hline
\end{tabular}

Table 1 Baseline Values of Key Input Parameters

Table 1 contains the baseline values of all the key TeDP design parameters for which energy consumption sensitivities are presented in this paper. The given fan the adiabatic efficiency is an estimate without distortion. The efficiency used in the baseline model is $94.35 \%$, which takes into account the $1 \%$ efficiency penalty due to ingesting the boundary layer. 


\begin{tabular}{|l|l|l|l|}
\hline $\begin{array}{l}\text { Cruise } \\
(35 \mathrm{kft} / \mathrm{M} 0.84 / \mathrm{ISA})\end{array}$ & $\begin{array}{l}\mathrm{N} 3 \mathrm{~A} / \mathrm{UHB} \\
\text { (installed -2 eng) }\end{array}$ & $\begin{array}{l}\text { N3-X/BSCCO } \\
\text { (installed) }\end{array}$ & $\begin{array}{l}\text { N3-X/MgB } \\
\text { (installed) }\end{array}$ \\
\hline Fn $-\mathrm{lbf}$ & 21,957 & 23,018 & 22,933 \\
\hline TSFC $-\mathrm{lbm} / \mathrm{hr} / \mathrm{lbf}$ & 0.4455 & 0.3549 & 0.3336 \\
\hline TSEC - BTU/s/lbf & 2.085 & 1.832 & 1.8094 \\
\hline BPR & 25.7 & 28.8 & 29.3 \\
\hline OPR & 80.1 & 84.9 & 85.0 \\
\hline T3 $-\mathrm{R}$ & 1670.5 & 1677.5 & 1677.7 \\
\hline T4 - R & 3260 & 3260 & 3260 \\
\hline Wair $-\mathrm{lbm} / \mathrm{s}$ & 2904 & 2596 & 2587.2 \\
\hline Vbypass-Inlet $-\mathrm{ft} / \mathrm{s}$ & 817 & 742 & 742 \\
\hline Vbypass-Nozzle $-\mathrm{ft} / \mathrm{s}$ & 989 & 986 & 986 \\
\hline Vcore-Inlet $-\mathrm{ft} / \mathrm{s}$ & 817 & 817 & 817 \\
\hline Vcore-Nozzle $-\mathrm{ft} / \mathrm{s}$ & 1559 & 1415 & 1418 \\
\hline
\end{tabular}

Table 2 Cruise Performance Comparison N3A/UHB and N3-X/TeDP Propulsion Systems

\begin{tabular}{|l|l|l|l|}
\hline $\begin{array}{l}\text { RTO } \\
\text { (SL/M0.30/ISA+27R) }\end{array}$ & $\begin{array}{l}\text { N3A/UHB } \\
\text { (installed - 2 eng) }\end{array}$ & $\begin{array}{l}\text { N3-X/BSCCO } \\
\text { (installed) }\end{array}$ & $\begin{array}{l}\text { N3-X/MgB } \\
\text { (installed) }\end{array}$ \\
\hline Fn $-\mathrm{lbf}$ & 72,623 & 57237 & 57,233 \\
\hline TSFC $-1 \mathrm{bm} / \mathrm{hr} / \mathrm{lbf}$ & 0.2777 & 0.2652 & 0.2495 \\
\hline TSEC - BTU/s/lbf & 1.443 & 1.3685 & 1.348 \\
\hline BPR & 29.59 & 34.9 & 35.6 \\
\hline OPR & 56.8 & 56.5 & 56.6 \\
\hline T3 - R & 1806.4 & 1809.4 & 1809.7 \\
\hline T4 - R & 3360.0 & 3360 & 3360 \\
\hline Wair $-\mathrm{lbm} / \mathrm{s}$ & 6622 & 5842 & 5831 \\
\hline Vbypass-Inlet $-\mathrm{ft} / \mathrm{s}$ & 343 & 320 & 320 \\
\hline Vbypass-Nozzle - ft/s & 691 & 632 & 632 \\
\hline Vcore-Inlet - ft/s & 343 & 343 & 343 \\
\hline Vcore-Nozzle - ft/s & 904 & 779 & 780 \\
\hline
\end{tabular}

Table 3 Rolling Take-off Performance Comparison of the N3A/UHB and N3-X/TeDP Propulsion Systems

The N3-X and the TeDP propulsion system have continued to be updated and refined since the previously reported results ${ }^{2}$. Therefore updated performance results using the design values given in Table 1 are presented in Table 2 and Table 3. The resulting cruise TSFC and propulsion system weight and the mission energy consumption that corresponds to that combination of TSFC and propulsion system weight are used as the baseline value against which the parametric results are measured.

Included in these tables is the performance of the N3A/ulta-high bypass (UHB) geared turbofan. The N3A uses the same HWB airframe as the N3-X and has the same payload, range and cruising speed. The UHB engine is a geared turbofan that uses all the same technology design parameters as was used in the TeDP. Comparison to the $\mathrm{N} 3 \mathrm{~A} / \mathrm{UHB}$ allows the energy consumption reduction due to the boundary layer ingesting distributed propulsion aspect of the TeDP system to be separated from the lower drag of the HWB aircraft and the advanced turbomachinery technology.

\begin{tabular}{|l|l|l|l|}
\hline & $\mathrm{N} 3 \mathrm{~A} / \mathrm{UHB}$ & $\mathrm{N} 3-\mathrm{X} / \mathrm{BSCCO}$ & $\mathrm{N} 3-\mathrm{X} / \mathrm{MgB}_{2}$ \\
\hline Fans - lbs & 8615 & 5494 & 5494 \\
\hline Core Engines/Turboshafts - lbs & 9364 & 7163 & 7369 \\
\hline Gearbox/Electrical System - lbs & 1111 & 14,087 & 12,694 \\
\hline Inlet/Nacelles/Nozzles/Tanks - lbs & 8099 & 11,363 & 11,378 \\
\hline Pylon - lbs & 3480 & 0 & 0 \\
\hline Total Propulsion System - lbs & 30,670 & 38,108 & 36,936 \\
\hline
\end{tabular}

Table 4 Weight comparison of the N3A/UHB and N3-X/TeDP Propulsion Systems 
The electrical system and turbomachinery weight estimates have been updated and refined as well. Table 4 compares the N3A/UHB weights to the BSCCO/Cryocooler and $\mathrm{MgB}_{2} / \mathrm{LH} 2$ configurations of the N3-X/TeDP. The TeDP doesn't break down into identifiable engines and so the comparison of the full TeDP propulsion systems must be to the sum of the two UHB engines. The TeDP systems are still heavier than the UHB turbofans, although the sum of the 14 individual fans in the TeDP system weighs considerably less than the two large fans on the UHB with roughly the same area. The total area of the 14 47-inch diameter fans in the TeDP system is 22,033 in $^{2}$, versus $23,188 \mathrm{in}^{2}$ for the 2 UHB engines.

777-200LR Class Vehicle Mission Fuel Consumption 279,800 lbs, Mission Energy Consumption = 5.199e09 BTU

\begin{tabular}{|l|lr|l|l|l|}
\hline $\begin{array}{l}\text { Superconducting Material / } \\
\text { Cooling Method }\end{array}$ & $\begin{array}{l}\text { TSFC @ } \\
\text { ft/M0.84 } \\
\text { Continuous } \\
\text { lbm/hr/lbf }\end{array}$ & $\begin{array}{r}\text { Max } \\
-\end{array}$ & $\begin{array}{l}\text { Total Propulsion } \\
\text { System Weight - lbs }\end{array}$ & $\begin{array}{l}\text { Mission } \\
\text { Energy } \\
\text { Consumption - } \\
\text { BTU }\end{array}$ & $\begin{array}{l}\text { Reduction } \\
\text { compared to } \\
777-200 L R\end{array}$ \\
\hline BSSCO/Cryocooler & 0.3549 & 38,108 & $1.8703 \mathrm{e} 09$ & $-62.9 \%$ \\
\hline $\mathrm{MgB}_{2} / \mathrm{LH} 2$ & 0.3336 & 36,936 & $1.8297 \mathrm{e} 09$ & $-63.8 \%$ \\
\hline
\end{tabular}

Table 5 N3-X Baseline TSFC, Weight, Mission Energy Consumption and Energy Reduction Compared to the 777-200LR

Table 5 presents the baseline TSFC at the 35,000 ft, M0.84 max continuous condition, the total propulsion system weight and the mission energy consumption for the N3-X/TeDP system with either the BSCCO superconducting material cooled by mechanical cryocooler refrigeration or the $\mathrm{MgB}_{2}$ superconducting material and liquid hydrogen cooling. The TSFC, propulsion weight and mission energy consumption given in the percent reduction in mission energy consumption is relative to the NASA estimate of the energy consumption of a Boeing 777-200LR class aircraft with a GE90-112B class engine flying the same mission, with the same payload and at the same cruise speed.

\section{Analysis}

The change in mission energy consumption due to perturbations of each of the design parameters is presented here. Since the baseline values represent the highest anticipated performance, the perturbations are all in the direction of lower performance. Using the NASA Flight Optimization System (FLOPS) ${ }^{4}$ model of the N3-X/TeDP system the total mission fuel mass was determined for a wide range of assumed cruise TSFC and propulsion weight values. The Numerical Propulsion System Simulation (NPSS) ${ }^{5}$ model of the TeDP was then run for a parametric range of value for each key design parameters given in Table 1. The cruise TSFC and propulsion weight for each parametric value was determined. The mission fuel mass was obtained from the FLOPS model. For systems that used cryocoolers for superconductor cooling the mission fuel consumption was directly converted to mission energy consumption by multiplying by the $18580 \mathrm{BTU} / \mathrm{lbm}$ LHV of jet fuel. For systems that used liquid hydrogen (LH2) an estimate was made of the split between total hydrogen weight and total jet fuel weight. The same LHV was used to determine the amount of energy in the jet fuel. A LHV of $51590 \mathrm{BTU} / \mathrm{lbm}$ was assumed for hydrogen and was used to obtain the energy contained in the hydrogen which is then added to the energy contained in the jet fuel to give the total fuel total energy.

Table 1 presents the highest anticipated values for each parameter that could reach a TRL of 4-6 by 2030 . As such the perturbations to the parameters are only in the direction of lower performance. The exception is the fan pressure ratio (FPR) which is a design choice rather than an anticipated technology limit so values above and below the 1.30 baseline value were examined. 


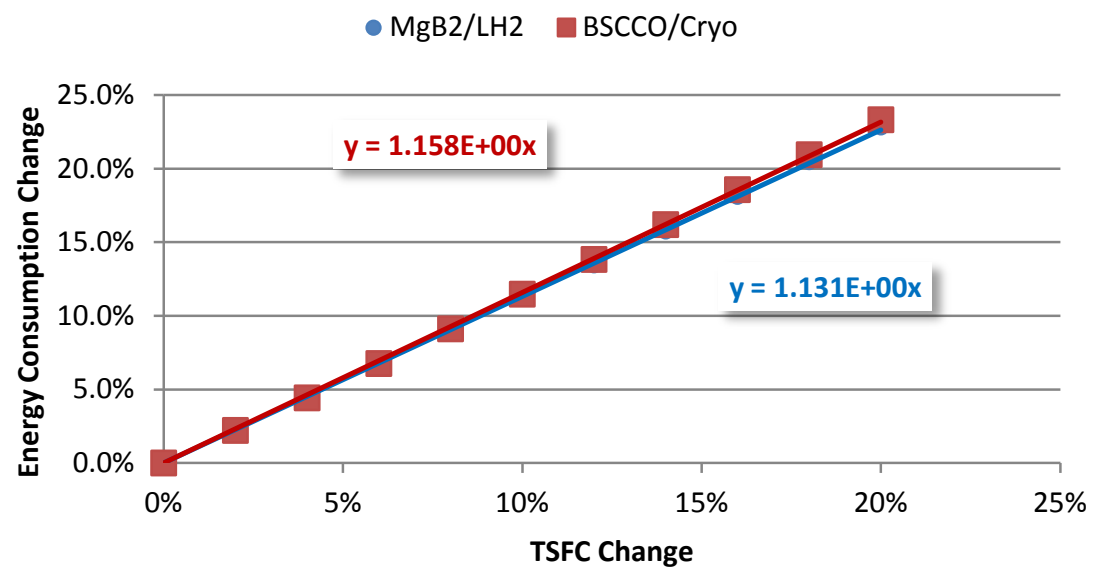

Figure 4 Changes in Mission Energy Consumption vs TFSC Increase

The mission energy consumption estimates were obtained by running a model of the N3-X in the NASA Flight Optimization system (FLOPS) for a parametric range of TSFC and propulsion system weight. The result was a set of 401 different fully converged estimates of the N3-X aircraft optimized over the given mission with the given payload. This was repeated for both superconducting material/cooling systems.

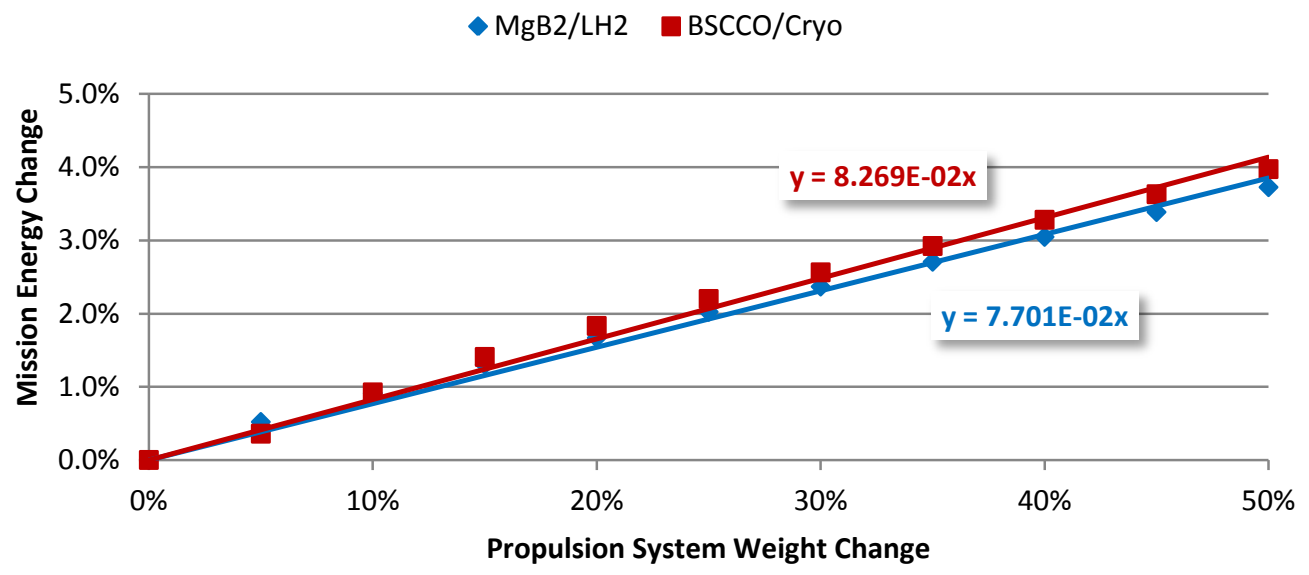

Figure 5 Mission Energy Consumption vs Propulsion Weight

Figure 4 represents the change in mission energy consumption as a function of the change in TSFC starting at the baseline with a constant propulsion system weight. Figure 5 represents the change in mission energy consumption as a function of propulsion system weight relative to at the baseline system weight with a constant TSFC value assumed.

Comparing these two plots shows that a one percent increase in TSFC yields slightly more than one percent increase in mission energy consumption while a ten percent change in propulsion system weight results in about the same one percent change in energy consumption. Thus, it can be seen that a technology that, for example, yielded a $3 \%$ reduction in cruise TSFC but weighed $10 \%$ more than the baseline propulsion system would still reduce the mission energy consumption by about $2 \%$.

In the rest of the analyses the change in cruise TSFC and propulsion system weight due to perturbation of a single design parameter is determined using the NPSS program. The TSFC and propulsion system weight are then used to read the parametric table generated by FLOPS to determine the mission fuel burn for that particular combination of TSFC and weight. The mission fuel weight was then converted to mission energy consumption. With the BSCCO/cryocooler configuration the calculation of the energy consumed over the course of the mission 
was straight forward since all the fuel is jet fuel and multiplying the total mission fuel burn by the LHV yields the total energy consumption. With the $\mathrm{MgB}_{2} / \mathrm{LH} 2$ configuration the amount of hydrogen can change as cooling needs change. This changes the TSFC since the hydrogen/jet fuel combination has a higher specific energy different than pure jet fuel. Thus less weight flow is needed to provide the same energy and so the total mission fuel weight is reduced. However, the higher heating value of hydrogen means that the change in total mission energy consumption not the same as the change in mission fuel weight. We estimated the weight of the total hydrogen by assuming that the ratio of hydrogen mass to jet fuel mass would be the same as the ratio between the hydrogen mass flow rate to the jet fuel mass flow rate at the $35,000 \mathrm{ft}$, M0.84 cruise condition. With the total mission fuel mass, the hydrogen/jet fuel ratio at cruise and the heating values of hydrogen and jet fuel we calculated the mission energy consumption.

Also the weight of the LH2 tanks changes as the amount of hydrogen changes. The LH2 tanks are bookkept as part of the propulsion system and so as the amount of hydrogen increases so too does the propulsion system weight. We assumed for this study that the hydrogen tanks would weigh half of the weight of the hydrogen they contained.

A technology development challenge that is unique to a propulsion system that using electricity to transmit the primary propulsion power is the development of very high power to weight and very low loss superconducting electric motors and generators. The key to high efficiency is controlling the AC losses in the stator. The reason for these losses is that while superconductors have zero electrical resistance when carrying a DC current, they are subject to three separate loss mechanisms when operating in an AC field: hysteresis losses, filament coupling losses, and eddy currents, . The eddy current losses are a function of the wire size. The coupling losses are a function of the pitch length of the twist of the filament bundle inside a given wire. And the hysteresis loss, which is unique to superconductors, is a function of the size of the individual superconducting filaments that make up a given wire. The primary challenge is to be able to make the individual superconducting filaments as thin as possible. The filament size assumed in the motors and generators in the baseline system is 10 microns. Current technology is yielding $\mathrm{MgB}_{2}$ filament sizes between 40 and 50 microns $^{6}$. There are some examples of superconducting wire with BSCCO filaments of approximately 20 microns, but the applicability to this application is not known at the time of writing. ${ }^{7}$

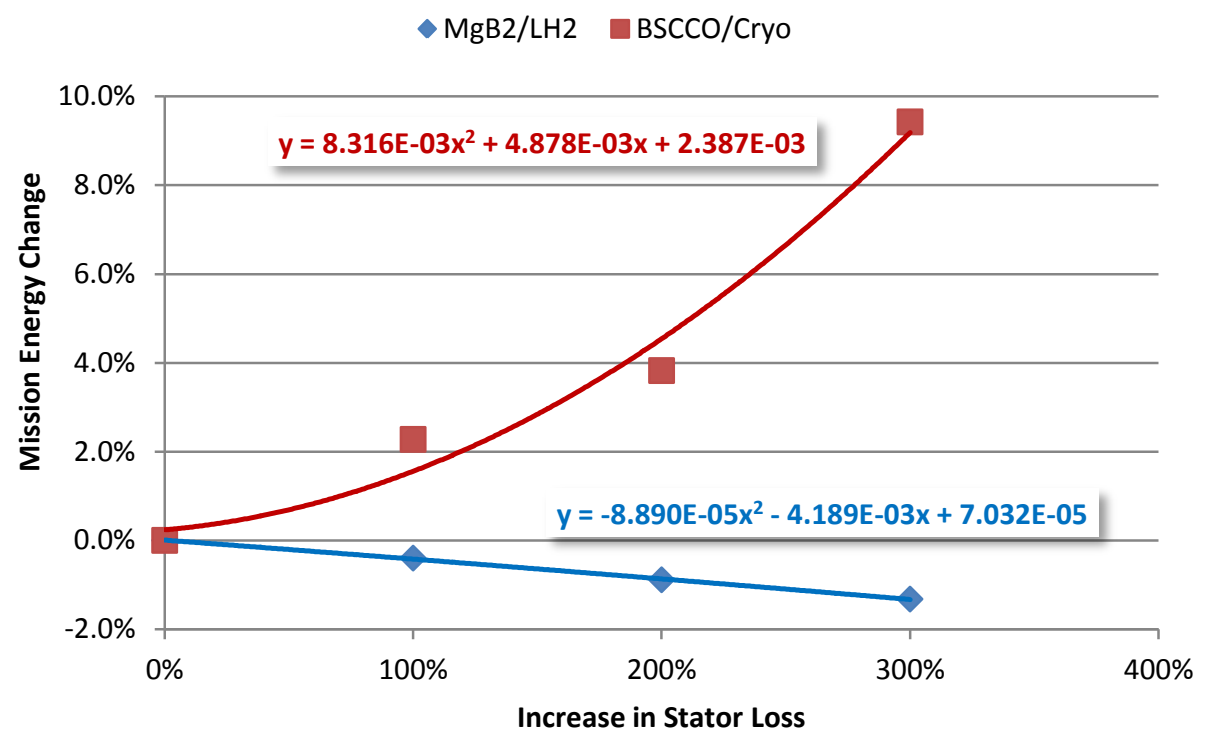

Figure 6 Mission Energy Change vs Percent Increase in Stator Loss

Figure 6 shows the response of mission energy consumption to changes in the total losses in the stators of the motors and generators. A range of up to 4 times the baseline losses was examined for both material and cooling combinations. A first order analysis of the losses for a $\mathrm{MgB}_{2}$ based motor at $4000 \mathrm{hp}$ and $3000 \mathrm{rpm}$ showed that for the baseline 10 micron filament size the hysteresis losses dominated at $415 \mathrm{~W}$, the coupling losses were second at $222 \mathrm{~W}$ and the eddy current losses were only $9 \mathrm{~W}$. When the filament size is increased to 40 microns the hysteresis losses increase to $1661 \mathrm{~W}$ while the other two losses remain unchanged since the wire size and twist pitch remained constant. The total losses went from $646 \mathrm{~W}$ for 10 micron to $1892 \mathrm{~W}$ for 40 micron or a $193 \%$ increase from the 
baseline. Thus the $300 \%$ range examined should cover the range in superconducting filament size from that possible today, to that anticipated as being possible by 2030 .

It might look like larger filaments with the higher losses are a good thing if liquid hydrogen is used to cool the system, but that is simply an artifact of the way the analysis was performed where only enough hydrogen is carried to meet the cooling requirements. What the negative slope of the $\mathrm{MgB} 2 / \mathrm{LH} 2$ line is actually saying is the more hydrogen on the vehicle the better regardless of whether it is needed for cooling. This would likely change if the energy required to generate and liquefy the hydrogen was included, as it should be, in the total energy consumption. However, in order to keep the energy accounting comparable, the energy required to extract, transport and refine the jet fuel would also have to be included in the mission energy consumption. Determining the energy expended making the fuels is beyond the scope of this study.

Other factors such as the ability to extract the energy from the filament to avoid heat build-up are likely to maintain a focus on reducing filament size. The results of this analysis simply show that with cryocoolers and especially liquid hydrogen cooling, motors and generators with the current filament sizes appear to yield systems that still meet the $\mathrm{N}+3$ energy reduction goals.

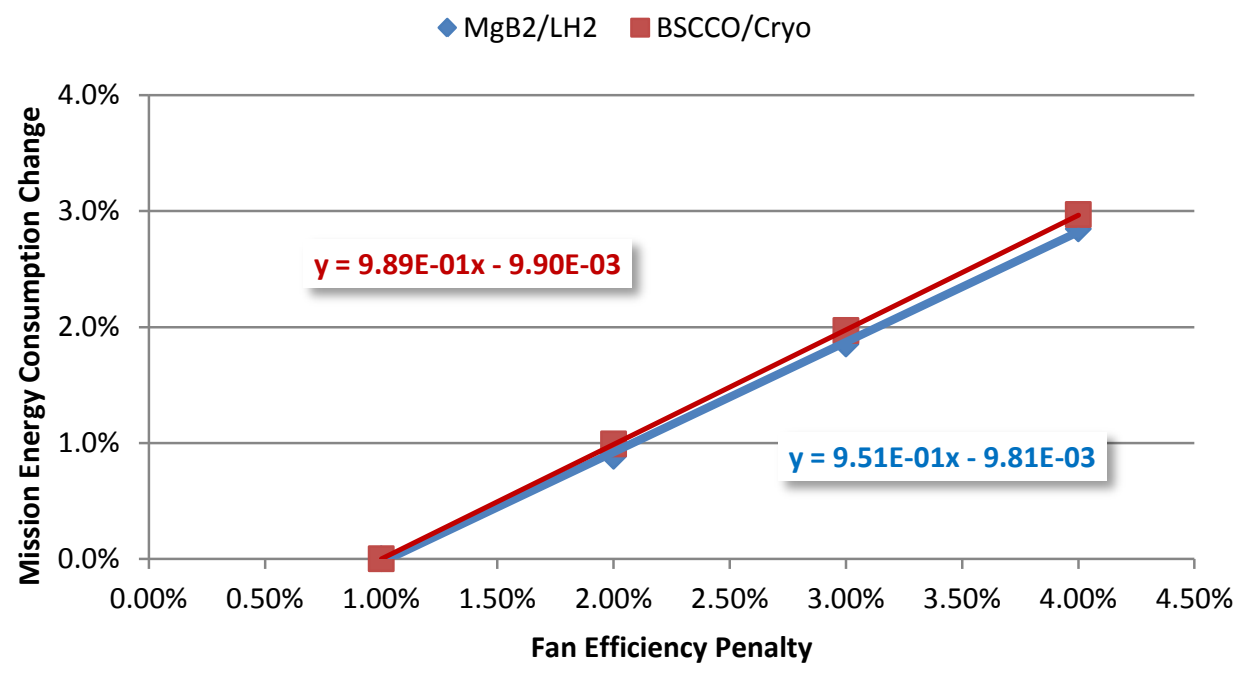

\section{Figure 7 Mission Energy Consumption Change vs Fan Efficiency Penalty}

The main reason for using an electrical distribution system is to allow an arbitrary number of propulsors and power sources. The power source or sources could come from on-board generation or stored energy devices such as batteries or both. Further, the electrical system allows the location of the propulsors to be largely independent of the location and type of the power source. For the N3-X this flexibility allows an array of propulsors with many small propulsors to be spread across as much of the span of the aircraft as possible in order to capture as much of the boundary layer as possible while allow still keeping the driving turboshaft engines as large as possible and located to take in clean freestream air. The large size and freestream location allows the maximum thermal efficiency in the turboshaft engines. However, the high velocity gradient across the boundary layer results in a very high distortion index for the propulsor fans. This high distortion index can cause a considerable loss in fan adiabatic efficiency unless active or passive flow control measures are taken. However, these measures can result in additional pressure loss in the inlet. A study by UTRC and Pratt \& Whitney indicated that by careful sculpting of the inlet, both the total pressure loss and the distortion penalty on the fan can be greatly reduced ${ }^{8}$. Their best estimate is that inlet pressure loss of as little as $0.5 \%$ and $1 \%$ efficiency penalty might be possible from an inlet and fan designed together. The $0.5 \%$ inlet pressure loss and $1 \%$ BLI penalty on efficiency was used as the baseline values for the N3-X/TeDP. 


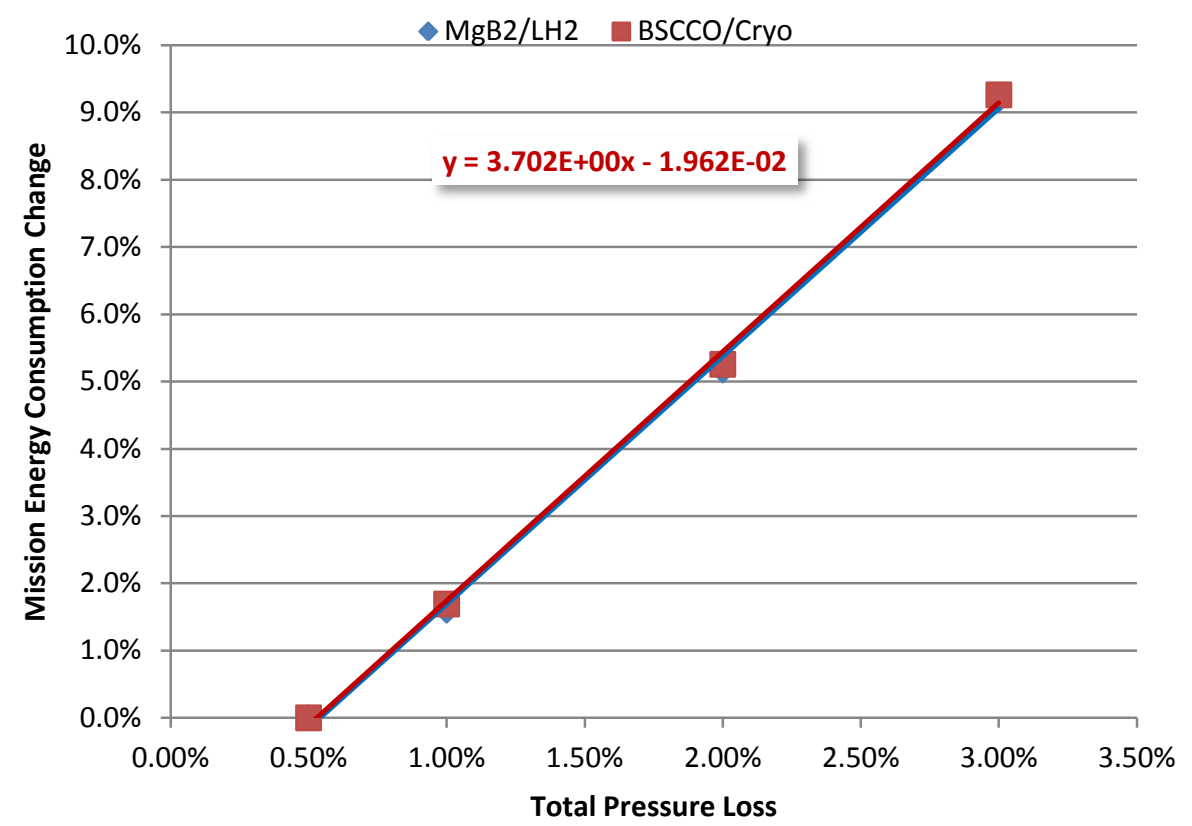

Figure 8 Mission Energy Consumption vs Propulsor Inlet Total Pressure Loss

Figure 7 and Figure 8 show that the mission energy consumption is very sensitive to inlet total pressure loss and somewhat less sensitive to changes in fan efficiency. These two plots indicate that efforts to reduce inlet distortion that also result in a higher total pressure drop might have the intended effect of increasing fan efficiency yet still result in an increase in mission energy consumption due to the pressure drop in the inlet. While the change in fan efficiency is being attributed to distortion due to boundary layer ingestion, the plot is valid for any change in fan efficiency regardless of the source of the change.

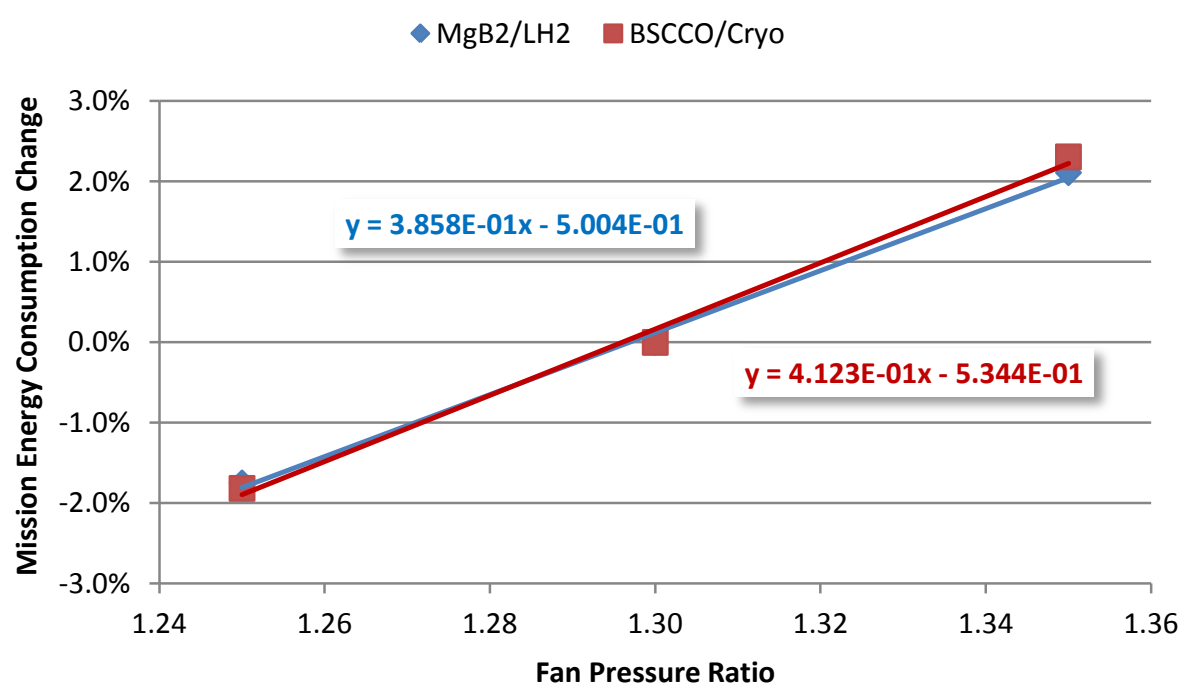

\section{Figure 9 Mission Energy Consumption Change vs Fan Pressure Ratio}

Another key factor in the initial fan efficiency, as well as the amount of efficiency lost to a given amount of inlet distortion, is the fan pressure ratio (FPR). The higher the FPR the more distortion tolerant the fan is and the lower the efficiency penalty. The FPR of the baseline model was set at 1.30. Figure 9 shows the impact on mission energy consumption for changes in FPR between 1.25 and 1.35. 


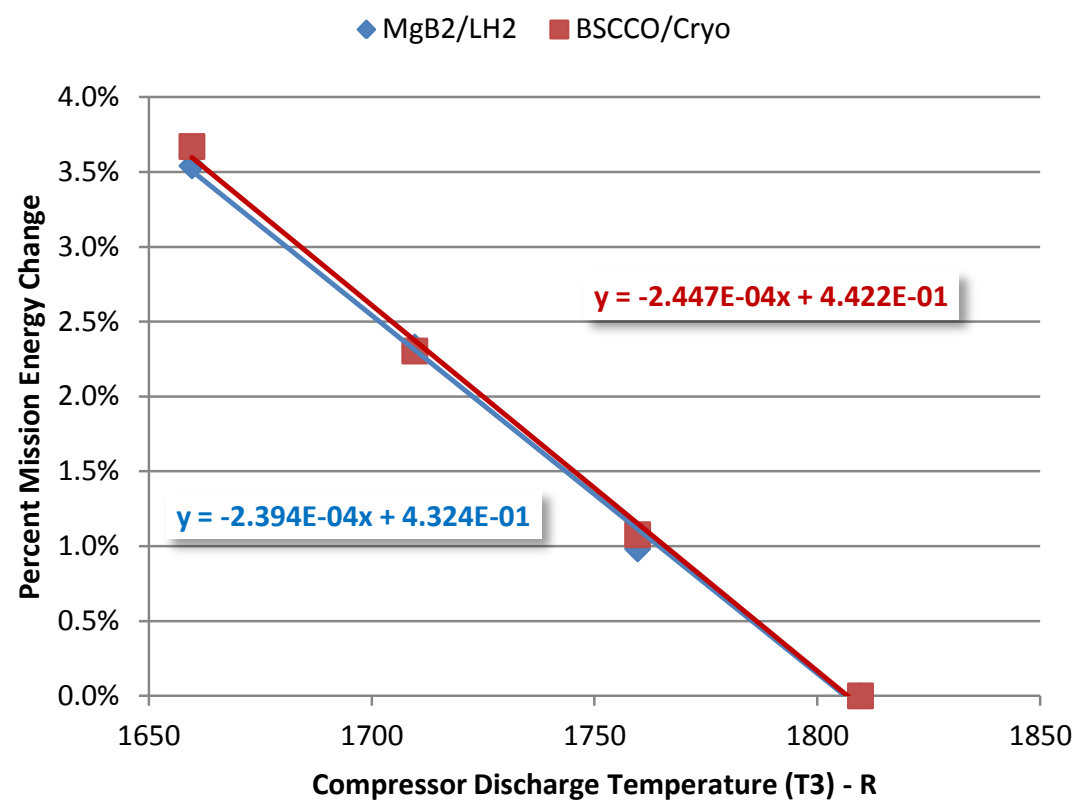

Figure 10 Mission Energy Consumption vs Compressor Exit Temperature (T3)

The overall pressure ratio (OPR) of each of the turboshaft engines is determined by the maximum compressor discharge gas path temperature (T3), with a minimum last stage blade height of 0.5 inches in the CompH as a constraint. The baseline value of maximum T3 is $1810 \mathrm{R}(1350 \mathrm{~F})$. The impact of reducing maximum T3 by as much as $150 \mathrm{R}$ was examined. Reducing the T3 over this range reduced the OPR at the RTO flight condition from 56.6 at $18107 \mathrm{R}$ to 31.4 at $1660 \mathrm{R}$. Figure 10 shows that a $150 \mathrm{R}$ reduction of maximum $\mathrm{T} 3$ increases mission energy consumption by about $3.5 \%$.

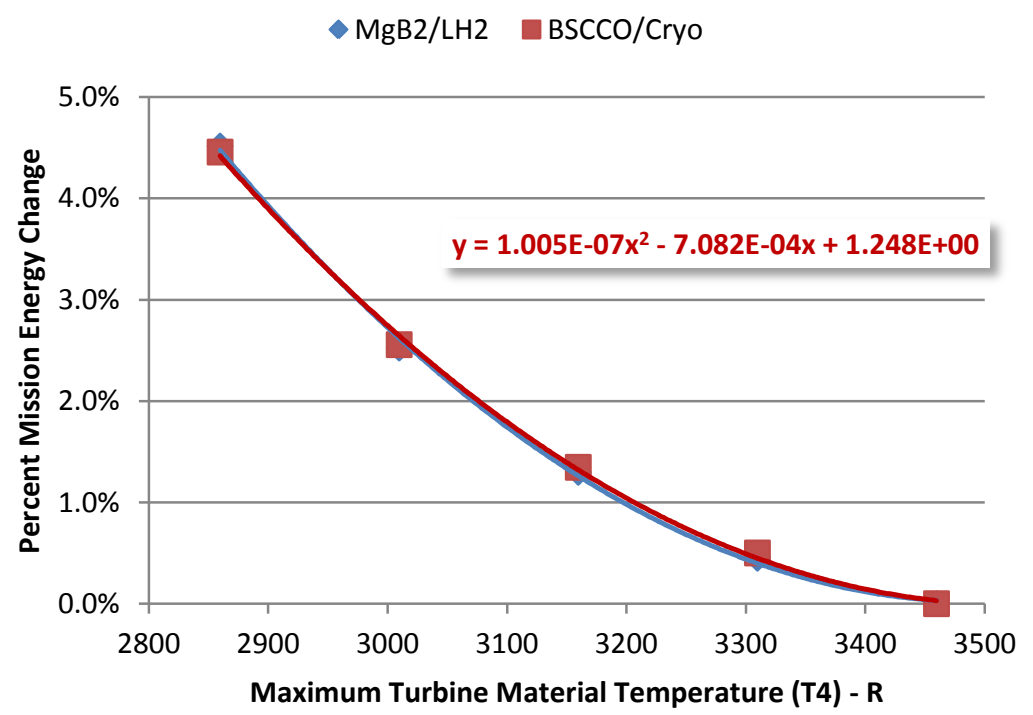

Figure 11 Mission Energy Consumption vs Turbine Inlet Temperature (T4)

The turboshaft engine is assumed to use Ceramic Matrix Composite (CMC) materials throughout the hot section including turbine stator and rotor blades. All blades are assumed to be uncooled, though the turbine disks continue to require some cooling flow. The baseline model assumes a $3460 \mathrm{R}(3000 \mathrm{~F})$ maximum material temperature ${ }^{9}$. CMC materials with a $2860 \mathrm{R}(2400 \mathrm{~F})$ maximum material temperature are being used in engines under development

11

American Institute of Aeronautics and Astronautics 
today ${ }^{10}$. So a range of turbine material temperatures between these temperatures was examined. The turbine inlet gas temperature in the NPSS model was reduced $100 \mathrm{R}$ from the maximum material temperatures to provide a margin of safety. Figure 11 shows that the change in energy consumption is not linear with temperature. As a result, a $150 \mathrm{R}$ reduction from $3460 \mathrm{R}$ to $3310 \mathrm{R}$ increases mission energy consumption by $0.5 \%$, while the same $150 \mathrm{R}$ reduction from $3010 \mathrm{R}$ to $2860 \mathrm{R}$ results in a energy consumption increase of $2.4 \%$.

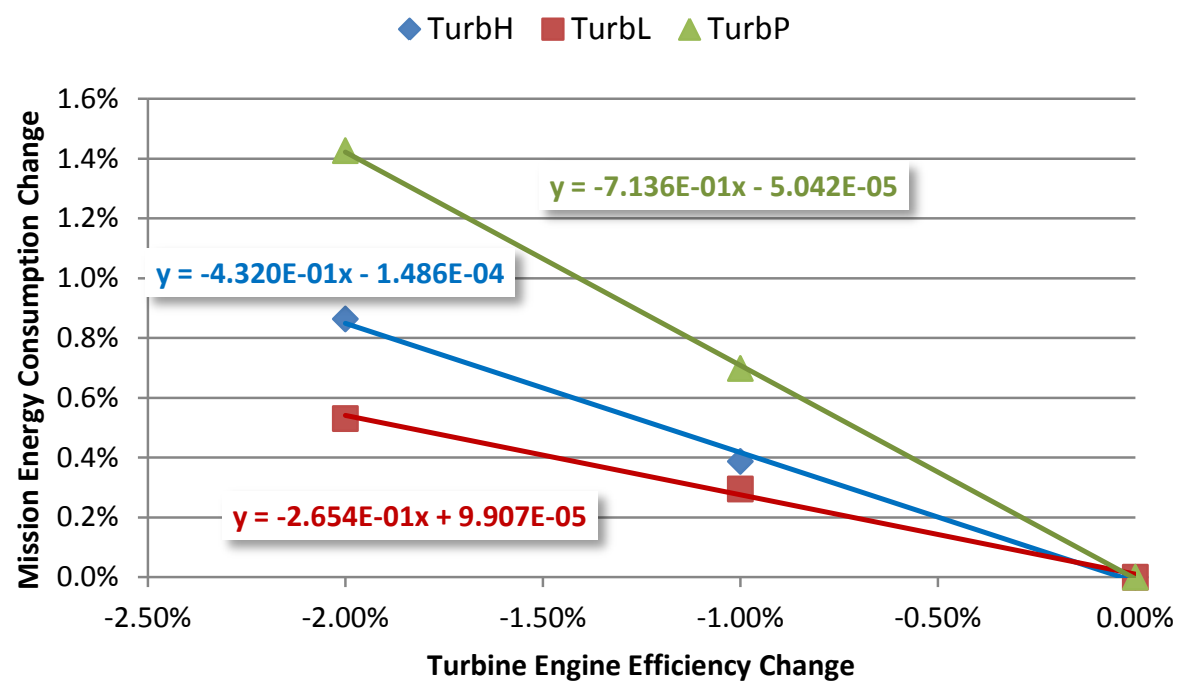

Figure 12 Mission Energy Consumption Change vs Turbine Polytropic Efficiency Change

There are three turbines in the turboshaft engine. Figure 12 illustrates that the mission energy consumption is not very sensitive to changes to efficiency in the gas generator turbines (TurbH and TurbL), while it is about twice as sensitive to changes in the power turbine (TurbP) which drives the generator. There was no difference in energy consumption between the two different superconductor/cooling combinations, so only one line is shown for each component and the sensitivity for the three turbines combined onto a single plot.

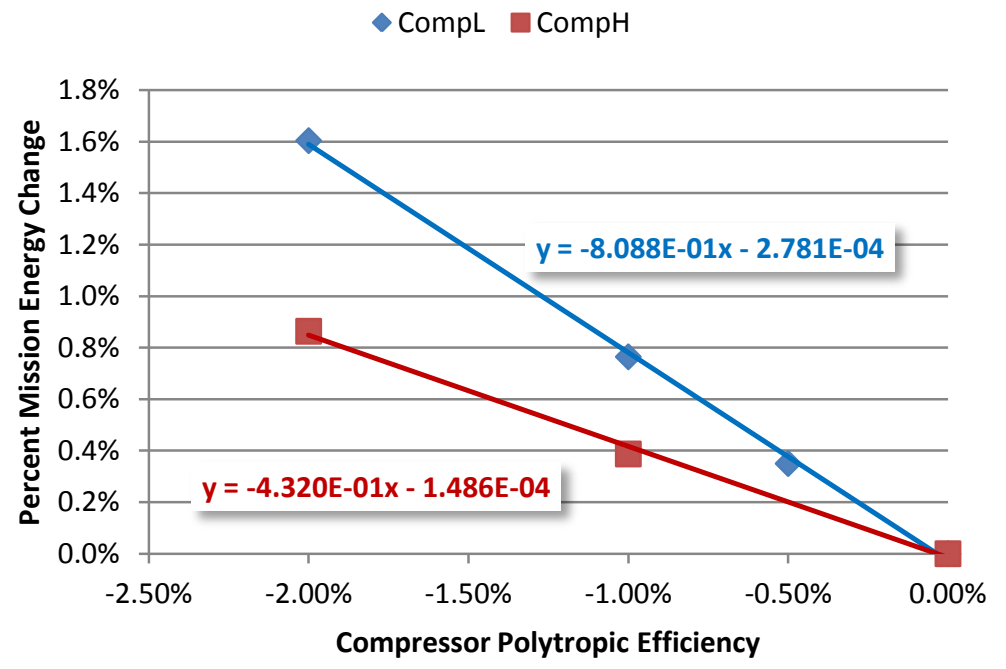

Figure 13 Mission Energy Consumption Change vs Compressor Polytropic Efficiency Change

There are two axial compressors in the turboshaft engine. Figure 13 shows that the mission energy consumption is much more sensitive to changes in the efficiency of the first compressor, CompL, compared to the changes in efficiency of the second compressor, CompH. As for the turbines, there was no difference between the two 
superconductor/cooling combinations for the sensitivity of energy consumption to compressor efficiency. Therefore, a single line is presented for each compressor and the sensitivity for both compressors is presented on the same plot.

\section{Conclusion}

One of the primary concerns with a turboelectric propulsion system is the additional weight of the electrical system since it seems, on first examination, that adding 14,000 lbs of motors, generators, power electronics and transmission equipment in replacement of a simple shaft and gearbox could not result in fuel savings. The comparison, however, is not that simple. The TeDP configuration also reduces weight. It saves weight by eliminating the gearbox and pylon as well as reducing the fan weight by $36 \%$ compared to that of a baseline UHB turbofan that was sized to power the N3A. It also reduces the propulsion system weight by the simple fact that better fuel efficiency of the TeDP system reduces the fuel load which allows the aircraft to be smaller and lighter and in turn reducing the thrust required so the entire TeDP system can be smaller and lighter. The end result is that the installed weight of the TeDP is only between 6300 and $7400 \mathrm{lbs}$ heavier than the UHB despite the addition of between 12,700 and 14,000 lbs of electrical motors, generators and power electronics. This paper shows that the energy consumption of the $\mathrm{N} 3-\mathrm{X}$ only increases about $0.8 \%$ for every $10 \%$ increase in propulsion system weight, assuming that the TSFC remains the same. This means the extra weight of the TeDP system would impose a $1.4 \%$ to $1.8 \%$ energy consumption penalty. The extra weight allows a propulsion system configuration that results in sufficient energy savings that more than compensates for the increase in consumption due to the heavier weight. The shallow slope of energy consumption to weight increase curve means that the weight estimates of the electrical system could increase by a considerable amount without negating the energy consumption savings of the distributed propulsion system.

The other primary concern is the ability to make superconducting motors and generators with superconducting filaments of sufficiently small diameter to keep losses low in the stator. Our analysis shows that when using cryocoolers, the losses in the stators could be double or triple of those of the baseline without unacceptable increases in mission energy consumption. Today's best filaments in $\mathrm{MgB}_{2}$ are in the range of 40-50 microns. A 40 micron filament would result in a $200 \%$ increase in stator losses. The stator losses start out so low that, even including heavier cryocoolers and the extra energy to drive them, the mission energy consumption increases about $3.8 \%$. The energy reduction compared to the B777-200LR would drop from $62.9 \%$ to $60.6 \%$. This means that even with today's superconducting filaments a turboelectric distributed propulsion system appears to be able to meet the N+3 energy reduction metric. When cooled with liquid hydrogen, increases in stator losses have the counterintuitive result of decreasing the mission energy consumption. This is due to the fact that hydrogen is used as a fuel after it is used as a coolant and as such counts ultimately as part of the fuel weight. The higher LHV of hydrogen means that for every additional pound of hydrogen required to cool the motors and generators there are three fewer pounds of jet fuel required. The propulsion weight does increase due to the larger, heavier hydrogen tanks required, but this increase is about a sixth of the decrease in jet fuel weight. Thus there is a substantial net decrease in the vehicle takeoff weight. For example, a 300\% increase in stator loss results in a 16\% reduction in total fuel weight (hydrogen + jet fuel). The reduction in mission energy consumption due to lower fuel weight is greater than the increase in energy consumption due to energy losses in the motors and generators. The net result is a mission energy consumption reduction of $1.1 \%$. Thus hydrogen cooling represents a way to accommodate higher losses including those from current technology superconducting filaments without the added penalty of larger and more power consuming cryocoolers.

The N3-X total mission energy consumption is highly sensitive to pressure loss in the inlet of the propulsors, while somewhat less sensitive to adiabatic efficiency loss in the fan. This suggests that it is possible to add features to the inlet that reduce distortion transmitted to the fan and thus increase fan efficiency, yet still increase energy consumption due to pressure losses in the inlet from those features. The converse situation can be true as well. The highly coupled nature of an embedded inlet and fan suggests that they should be treated as a single component, and analyzed and optimized as a unit.

Examining the relationship between energy consumption and turbine inlet temperature shows that while it is desirable to increase the turbine inlet temperature to highest value possible in order to yield the maximum possible reduction in energy consumption, meeting the target energy consumption savings does not hinge on the development of a $3000 \mathrm{~F} \mathrm{CMC}$ material. For example, if the maximum CMC material temperature obtainable is $2700 \mathrm{~F}$ instead of $3000 \mathrm{~F}$ there would be a $1.3 \%$ increase in energy consumption. In terms of the $\mathrm{N}+3$ metric of energy savings relative to today's best aircraft, reducing the CMC temperature limit from $3000 \mathrm{~F}$ to $2700 \mathrm{~F}$ reduces the energy savings from $62.9 \%$ to $62.4 \%$, and $63.8 \%$ to $63.3 \%$, for $\mathrm{BSCCO} / \mathrm{Cryo}$ and $\mathrm{MgB}_{2}$ systems, respectively. . 


\section{Acknowledgments}

We would like to thank the NASA Subsonic Fixed Wing project for their ongoing support and encouragement as we endeavor to "think outside the nacelle".

\section{References}

${ }^{1}$ Del Rosario, R., Follen, G., Wahls, R. Madavan, N, "Subsonic Fixed Wing Project Overview and Technical Challenges for Energy Efficient Environmentally Compatible Subsonic Transport Aircraft", 50th AIAA Aerospace Science Meeting, Nashville, TN, 9-12 Jan. 2012

${ }^{2}$ Felder, J., Brown, G., Kim, H., Chu, J., "Turboelectric Distributed Propulsion in a Hybrid Wing Body Aircraft", 20 th $I S A B E$ Conference, Götenberg, Sweden, 12-16 Sept., 2011

${ }^{3}$ NASA Research and Technology Program and Project Management Requirements, NASA Procedural Requirements 7120.9. Appendix J. Technology Readiness Levels (TRLs), February 05, 2008

${ }^{4}$ NPSS User Guide Software Release: NPSS_1.6.5

${ }^{5}$ McCullers, L. A.: “FLOPS Weight Module Documentation, Wate.doc,” FLOPS Users Manual, updated April 2008

${ }^{6}$ Rindfleisch, M., "Low AC-Loss Magnesium diboride Superconductors for Turbo-electric Aircraft Propulsion Systems", Hyper Tech Research, Inc., Columbus, OH, NASA Contract NNX09CC75P, 22 July, 2009

${ }^{7}$ Liu, X. T., Le, Q. V., Schwartz, J., "Influencing Factors on the Electrical transport Properties of Spit-Melt Processed Bi2Sr2CaCu2Ox round wires", Department of Materials Science and Engineering, North Carolina State University, Raleigh, NC, Superconducting Science and Technology, No. 25, 31 May, 2012

${ }^{8}$ Tillman, Greg, et all, "Robust Design for Embedded Engine Systems - BLI Inlet and Distortion-Tolerant Fan Design", NASA Contract Number NNC07CB59C, 2010

${ }^{9}$ Grady, J, "Overview of CMC Research at the NASA Glenn Research Center", $35^{\text {th }}$ Annual Conference on Composites, Materials and Structures”, 24-27 Jan., 2011

${ }^{10}$ GE Reports, "Not Your Mother's China: New Ceramic Composites are Set to Revolutionize Aviation, Starting with the LEAP Engine", 5 July, 2012, URL: http://www.gereports.com/not-your-mothers-china/. 